\section{THE POSSIBILITY}

\section{DF SETTLING THE}

ISSUE OF ANIMAL

SUFFERING ON

\section{RATIONAL GROUNDS}

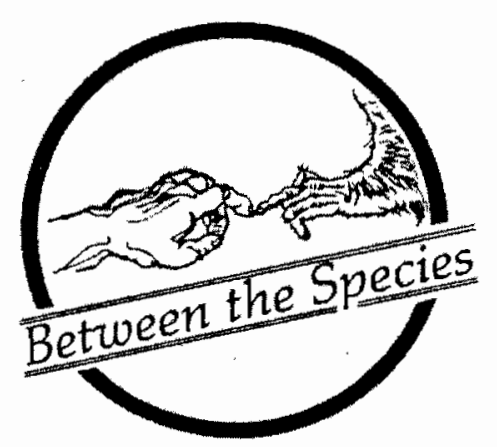

\author{
Judith Barad \\ Indiana State University
}

Jim Harter, Animals: 1419 Copyright-Free Illustrations. New York: Dover, 1979
Professor Scriven's overall criticisms of utilitarianism as a justification for extending moral concern to animals are well argued. However, I do not think these criticisms warrant the conclusion that the "issue of how much we ought to be concerned about the suffering of animals is ... impossible to settle on rational grounds." Other rational grounds than utilitarianism can provide strong foundations on which to establish how much we ought to be concerned about the suffering of animals. Generally, I think inadequate attention has been given to an objective analysis of the ontological status of animals, an issue which some deontologists hold to be relevant to the moral status of animals. I will comment on Professor Scriven's paper in the order in which it is written before returning to this point.

The assumption underlying Professor Scriven's dismissal of deontological theories of animal rights seems to be that unless a theory rests on tradition, it cannot adequately support its claims. But narrowly confining ourselves to traditional philosophical views would result in turning back the clock on significant social and moral progress. For example, if we strictly adhered to Aristotle's views on the

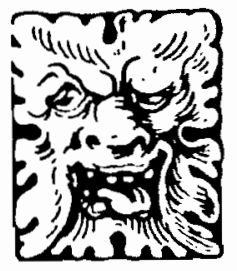

\section{DISCUSSION}


ontological status of women, we would fail to see the basis for extending equal rights to women. For a moral theory to be socially relevant, it should not ignore the findings of the empirical sciences. In the case of nonhuman animals, evolutionary theory has implications which are relevant to any deontological argument seeking to base rights upon a being's capacities or interests. Consequently, both nontraditional deontological theories and modified traditional deontological theories can add significant contributions to the debate over animals rights. Turning from deontology to preference utilitarianism, Professor Scriven criticizes Singer for inferring mental states from behavior, a criticism which could also apply to Regan. This passage is particularly problematic, in my view, for three reasons. First, neither Singer nor Regan can ever claim that animals are cognitively complicated enough to count as moral agents. In fact, Regan specifically says the animals are moral patients and not moral agents. ${ }^{1}$

Secondly, if we did not infer mental states from behavior, we would have no reason to help release someone from under a car who we see screaming and flailing around. Simply being under a car is not a sufficient reason to help this person, for he (a mechanic) may want to be there. The reason we would help him is that his behavior leads us to infer that his mental state is one of pain rather than pleasure. Generally, a result of failing to infer mental states from behavior would be increased indifference to the plight of others. The only way we recognize that others possess mental states other than by their behavior is by verbal articulation. Thus, if it is illegitimate to infer mental states from behavior, and if a person is not in the process of articulating his mental state to us, we cannot justifiably assume he is having one. If we do infer a mental state when a person is not using language, then "to the unconvinced," using Professor Scriven's words, "the inference is bound to look like so much question begging." Indeed, the only reason not to attribute mental states to animals on the basis of their behavior, and yet on the same basis attribute mental states to human beings, is the prejudice known as speciesism.

Finally, the rhetorical questions about rats and chickens knowing when they are in pain beg the very point at issue. ${ }^{2}$ Rats are very popular animals for pain experiments, a fact which would make little sense if they do not know when they are in pain. A rat knows when he is in pain, for when the scientist applies an irritating substance to his paw he behaves in a way consistent with how a being aware of pain would be expected to act. If we use the word "know" in the sense of "to be aware of," 3 then it is plausible to maintain that rats, like any other mammal, know when they are in pain. However, if we use the word "know" to mean some higher order cognitive capacity such as "to reflect on," then a person being stabbed with a knife cannot be said to "know" he is in pain.

\section{The only reason not to attribute mental states to animals on the basis of their behavior, and yet on the same basis attribute mental states to human beings, is the prejudice known as speciesism.}

The strongest arguments of Professor Scriven's paper are his criticisms of the utilitarian defense of animals. To base an animal's treatment on a favorable balance of pleasure over pain still leaves unanswered the important question of whether it is morally permissible to painlessly kill an animal.

Analyzing the justification of utilitarianism in regard to the animals issue, Professor Scriven examines the role of conscience. He argues that the only reason to have a conscience is self-interest and that "conscience is the result of programming." Granting that almost all utilitarians hold this view, the question of its truth remains. In cases where children react with horror and moral indignation upon seeing an animal killed, without encouragement from "moral teachers," the explanatory power of conscience as programming 
loses its force. Other philosophical views of conscience may be better able to take account of such responses. One such view, held by Aquinas, describes conscience as the result of both direct intuition into universal principles of action and of acquired knowledge and experience. He argues that conscience is an act of judgment which evaluates a particular action in view of a universal principle. Unlike behavioral programming, it cannot be extinguished, but it can be repressed. This view of conscience, although allowing for subjective factors, is not an artificially contrived response to societal norms for the sake of self-interest. Unlike the utilitarian conception, its emphasis on universal principles allows for altruism. The "Thou shall not kill" in this account of conscience does not differentiate between an American or an Ethiopian, for it is not based on such subjective factors as selfinterest or the degree to which a being is like me.

Emotively, Professor Scriven's observation is correct that my concern for my family is indeed greater than my concern for Ethiopians. But it is conscience which informs me that it is as morally wrong for the one to be killed as the other. Subjective preference can and should be distinguished from moral judgment. Logically, I disagree with Professor Scriven that the selfinterested account of conscience encounters a "hitch" in the analysis of criteria to judge which beings "are enough like me to warrant my respect and benevolence." Vegetarian feminists may claim that developed mammals which can use their capacities to enjoy their lives independent of others are not on the same ontological level as human fetuses, which are only in the process of developing into physically independent entities. If the vegetarian feminist subscribes to the self-interest theory, she could say that the chimp is like her in these respects whereas the fetus is not. Turning to Scriven's second example, a meateating antiabortionist may claim that although fetuses have the potential to develop into fully rational beings, chimps do not have this potential. Again, an antiabortionist proponent of self-interest would say that the fetus resembles him in this respect whereas the chimp does not. I do not grasp the point of the last example, since it is unlikely that a vegetarian environmentalist could claim to be like a redwood. In fact, the last example undermines the whole doctrine of conscience as self-interest. For an environmentalist may act to save redwoods out of altruistic concern that the entire planet not lose one of its most beautiful natural resources, even though knowing that he himself will never have the opportunity to experience their majesty.

Generally, to continually equate the ontological and moral status of fetuses and animals as Professor Scriven does (at least seven times) is an unwarranted assumption. As I pointed out, both antiabortionists and animal advocates could argue that the alleged equivalence is specious. Speaking for the animal advocates, it is a fact beyond speculation that nonhuman mammals can respond to their environment by moving to different locations, pursuing what they are attracted to and avoiding that which they perceive to be harmful. That a fetus can do so is more speculative. Given that whether or not a being should be extended certain rights is relevant to its possessing certain capacities, why should a two month old fetus be extended the same moral consideration as an adult chimpanzee? Observing a mother cow responding affectionately to her calf or lion cubs playfully interacting, it is legitimate to ask whether moral agents should respect these social abilities. On the other hand, it is just as pointless to consider whether or not to respect the social ability of the fetus as it is to consider whether or not to respect the right of a man to jump from the earth to the moon.

Ignoring an ontological asymmetry, Professor Scriven implies that we should not have the same concern for fetuses and cows as we have for our pets and our children. Although the fetus is clearly less developed and occupies a different ontological level from my child, it is not equally clear that a cow is a less developed being than my dog. Both the cow and the dog are physically independent mammals that have capacities to enjoy their own lives and pursue their own ends. The primary difference is a subjective one on the part of the pet owner based on emotional factors. But objectively speaking, does a dog have more intrinsic value than a cow?

Given that Professor Scriven has only considered subjective criteria for deciding who is qualified for membership in the moral community, I agree that such decisions are dangerous and would 
have terrible consequences. Nevertheless, it is not clear that objective criteria are similarly undesirable. For example, a being's ontological status as measured by its general psychological and physiological capacities could provide a criterion that is relatively free from prejudice for membership in the moral community.

The only warranted conclusion that can be drawn from Scriven's paper is that utilitarianism cannot provide adequate grounds for justifying the belief that animals should fall within our moral concern. But to admit that utilitarian theory is not up to this task does not automatically exclude other rational grounds for deciding how much we ought to be concerned about the suffering of animals. Consequently, by narrowing the field of theories available to those who seek to put the treatment of animals on a rational basis, Professor Scriven's paper has pointed toward more fertile theories which may justify the argument for animal rights.

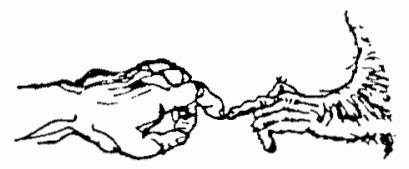

\section{$\underline{\text { Notes }}$}

${ }^{1}$ Tom Regan, The Case for Animal Rights (Berkeley: University of California Press, 1983), pp. 151-156.

2Dr. Irene Pepperberg at Northwestern University has conducted research on Alex, an African grey parrot, to determine whether or not he is capable of cognitive processes. She concludes, "What we've learned that we can do with him is to work with objects he's never before seen and question him about those objects, and he responds equally well, so obviously, some degree of processing is going on in his mind." If one species of bird can think isn't it premature to rule out-of-hand that other species of birds are incapable of thought?

Moreover, it is noteworthy that recently scientists have gathered from all over to discuss how and what animals think at a conference at Williams College in western Massachusetrs. For animal behaviorists and cognitive ethologists it is no longer a question of if animals think

${ }^{3}$ Webster's Dictionary.

\section{ON LOSING OUR YOUNG}

\section{I}

A nest built itself in summer

burden basket, bag of medicine

therein an exquisite cry

with babiest frail fledgling wrapped around this cry

with claw nagging heart fabric and pull

In our surroundings everything swelling, filling with

liquid -

blackberries burst to the ditch, exhausted

Mexicans were propping up gravenstein trees with boards

and the apples fell like bombs

honeysuckle spilling over fences drifting towards dogs

corn was cross-breeding and we didn't even know growing peculiar blue and yellow jewels beneath its skin

eucalyptus called to us with their medicinal oil ocean breaking coagulated sun

\section{II}

Night fell - a redwood with moon pinned under towards us wind tore down the road hunted something down the chimney windows blew out, stove ended up clear over there horses trying to gain on themselves in galloping circles

saw blowing world ran to beach looking for altar the original one

where my sisters moontide had rose red on the hearth

I lay with everything running out

broken wishbone in hand

raining body of water

A mare in the wind that heart kicked against my chest

You never left bent nest

but through these tears, a membrane of jewels

I envision you rising up every few minutes

out of my hands

taking wing over and over

a long thread of my sinew rides off with you

flying above queen anne's lace, seductive datura

dancing

in stripped stubble of field, wall of fog

the coastline rocks

and into the vortex, wings dripping light

Amy Trussell

Summer, 1986 